\title{
Microfluidic DNA-based potassium nanosensors for improved dialysis treatment
}

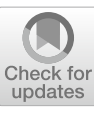

\author{
Alexander F. Smith ${ }^{1 \dagger}$, Bin Zhao ${ }^{2 \dagger}$, Mingxu You ${ }^{2}$ and Juan M. Jiménez ${ }^{1 *}$ (])
}

\section{*Correspondence:}

juanjimenez@umass.edu

${ }^{\dagger}$ Alexander F. Smith and Bin

Zhao contributed equally to this work

${ }^{1}$ Department of Mechanical

\& Industrial Engineering,

University of Massachusetts

Amherst, Amherst, MA 01003, USA

Full list of author information is available at the end of the article

\begin{abstract}
Background: Patients with end-stage renal disease (ESRD) have failed kidney function, and often must be treated with hemodialysis to extend the patient's life by artificially removing excess fluid and toxins from the blood. However, life-threatening treatment complications can occur because hemodialysis protocols are adjusted infrequently, as opposed to the kidneys which filter blood continuously. Infrequent blood tests, about once per month on average, are used to adjust hemodialysis protocols and as a result, patients can experience electrolyte imbalances, which can contribute to premature patient deaths from treatment complications, such as sudden cardiac death. Since hemodialysis can lead to blood loss, drawing additional blood for tests to assess the patient's kidney function and blood markers is limited. However, sampling multiple drops of blood per session using a microfluidic device has the potential to reduce not only the amount of blood drawn and avoid unnecessary venipuncture, but also reduce costs by limiting medical complications of hemodialysis and provide a more comprehensive assessment of the patient's health status in real time.

Result: We present preliminary proof-of-concept results of a microfluidic device which uses DNA-based fluorescence nanosensors to measure potassium concentration in a flowing solution. In a matter of minutes, the flowing potassium solution reduced the fluorescence intensity of the nanosensors to a steady-state value.

Conclusions: These proof-of-concept results demonstrate the ability of our DNAbased nanosensors to measure potassium concentration in a microfluidic device. The long-term goal is to integrate this technology with a device to measure potassium and eventually other blood contents multiple times throughout a hemodialysis session, enabling protocol adjustment similar to a healthy kidney.
\end{abstract}

Keywords: Potassium sensor, DNA nanosensor, G-quadruplex, Microfluidics, Fluorescence oligonucleotide

\section{Background}

In the USA alone, more than 726,000 patients suffer from kidney failure with more than 124,000 new yearly diagnoses and $28 \%$ mortality rate [1]. More than $71 \%$ of kidney failure patients require frequent hemodialysis to filter their blood artificially, and without dialysis the patient median survival time is only several weeks [2]. The goal of hemodialysis is to remove waste from the blood and maintain equilibrium of body fluids, functions naturally performed by the kidneys. During hemodialysis sessions, the patient's blood is pumped from their arm into a machine which uses a dialyzer to filter the blood

(c) The Author(s) 2019. This article is distributed under the terms of the Creative Commons Attribution 4.0 International License (http://creativecommons.org/licenses/by/4.0/), which permits unrestricted use, distribution, and reproduction in any medium, provided you give appropriate credit to the original author(s) and the source, provide a link to the Creative Commons license, and indicate if changes were made. The Creative Commons Public Domain Dedication waiver (http://creativecommons.org/publi cdomain/zero/1.0/) applies to the data made available in this article, unless otherwise stated. 
before it is infused back into the patient. The dialyzer contains two chambers, one for blood and one for dialysate, a solution of water, electrolytes, and salts. Toxins from the blood are diffusively transported across a semi-permeable membrane into the dialysate to provide artificial filtration that replaces the function of the kidneys.

In contrast to the kidneys, which function and adjust electrolytes continuously, adjustment of hemodialysis protocols and the dialysate is dependent on each dialysis center. Dialysates are adjusted infrequently and often prepared generically using a uniform concentration of electrolytes without consideration of each individual patient's blood electrolyte concentration. Blood electrolyte concentrations can be assessed by blood tests; however, these are costly, carry risks such as blood loss, anemia, hematoma, and infection, and can be impractical if required for each of the multiple weekly dialysis sessions [3-6]. Consequently, electrolyte levels, including potassium, are assessed infrequently and can contribute to blood electrolyte imbalances [7-9]. The leading cause of mortality in hemodialysis patients is sudden death due to cardiac arrest, which accounts for $45 \%$ of deaths [10-13]. Since potassium is the primary ion regulating cardiac repolarization, potassium imbalances have been hypothesized to trigger arrhythmias and contribute to sudden cardiac arrest in hemodialysis patients [11, 14]. Hence, monitoring potassium levels in hemodialysis patients is paramount.

Presently, blood electrolyte levels of dialysis patients are assessed with UV absorbance [15], optical [16, 17], or electrochemical [18-20] based assays that require large blood samples. Results commonly require $24 \mathrm{~h}$ or longer before they are received. More recently, molecular fluorescence-based techniques have been explored in research laboratory settings to measure potassium in solution [21, 22]. Molecular fluorescence-based assays have the potential of higher specificity and sensitivity than the more popular electrochemical (potentiometric) and electrical-impedance methods [23]. Advances in molecular sensing techniques have led to the development of novel DNA-based oligonucleotide nanosensors that can measure cations using G-quadruplex structures, where four guanines in a DNA strand encapsulate a monovalent ion in a plane [21]. While the physiological function of G-quadruplex structures is likely involved in DNA replication, transcription, and repair [24], with the addition of fluorescence dyes to the end of the GGGG sites, direct fluorescence measurement of electrolytes is possible [21]. G-quadruplex has been previously used for potassium ion detection. More recently, a selective potassium ion G-quadruplex sequence has been identified, with little interference from competitive ions at physiological concentrations [22].

In this study, based on the selective G-quadruplex sequence, we developed a firstgeneration microfluidic-based DNA nanosensor to measure potassium in an aqueous solution with the ultimate goal of measuring electrolytes in blood plasma at the point of care. In the device, fluorescence and quenching dyes FAM and DABCYL, respectively, are integrated into scaffold oligonucleotides rendering the DNA nanosensor. The DNA nanosensor is immobilized on the glass bottom of the device. Upon excitation, the absence of potassium results in light emission, while interaction between potassium and the DNA nanosensor leads to quenching of the fluorophore. Using the nanosensor, measuring serum electrolyte levels with a small sample volume in a point-of-care microfluidic device presents an opportunity to reduce clinical errors that can occur prior to sample analysis due to labeling, collection, and transport mishaps [25], in addition to 
reducing the amount of blood loss experienced by the patient. Furthermore, a microfluidic device allows for more frequent monitoring of a patient's electrolyte levels by measuring multiple drops of blood per hemodialysis session, providing a more comprehensive assessment of the patient's health.

\section{Methods}

\section{Preparation of oligonucleotide sample for DNA nanosensor}

The DNA nanosensor, composed of three hybridized oligonucleotides, was prepared by mixing $25 \mu \mathrm{M}$ fluorescence-emitting oligonucleotide (FAM), $25 \mu \mathrm{M}$ fluorescencequenching oligonucleotide (4-((4-(dimethylamino)phenyl)azo)benzoic acid, DABCYL) and $25 \mu \mathrm{M}$ oligonucleotide scaffold molecule in $0.1 \mathrm{M}$ phosphate buffer containing $0.85 \mathrm{mM} \mathrm{MgCl}\left(\mathrm{PB}+\mathrm{MgCl}_{2}\right)$. Varying magnesium concentration in the buffer solution during hybridization did not affect sensor affinity for $\mathrm{K}^{+}$(Fig. 1). The sample solution was heated for $5 \mathrm{~min}$ at $95^{\circ} \mathrm{C}$ to allow for annealing, and then stored for at least $15 \mathrm{~min}$ at room temperature to allow for DNA hybridization. The completed DNA-based sensor was analyzed for its sensing ability at room temperature but was stored at $-20{ }^{\circ} \mathrm{C}$ when not in use to keep the oligonucleotide structure stable. The formation of the DNA probe was characterized with a $16 \%$ native polyacrylamide gel electrophoresis (PAGE). The gel was run in $1 \times$ TBE under 100 volts for $30 \mathrm{~min}$ and imaged with Blue View transilluminator (Vernier) directly without staining.

\section{Fluorescence spectrum measurement}

A static fluorescence assay was performed with a fluorescence spectrometer (HORIBA, PTI fluorescence system) to test the function of the DNA nanosensor for $\mathrm{K}^{+}$sensing at room temperature. The DNA nanosensor at a concentration of $1 \mu \mathrm{M}$ was used and $\mathrm{K}^{+}$ was added at concentrations of $0,1 \mu \mathrm{M}, 1 \mathrm{mM}$, and $10 \mathrm{mM}$ to measure the change in fluorescence intensity. Potassium chloride $(\mathrm{KCl})$ was the source of $\mathrm{K}^{+}$for all experiments.

\section{DNA nanosensor concentration sensitivity}

A DNA nanosensor concentration assay was performed with a fluorescence spectrometer (HORIBA, PTI fluorescence system) in real time to further analyze the relationship of the DNA nanosensor concentration for constant $\mathrm{K}^{+}$concentrations at room

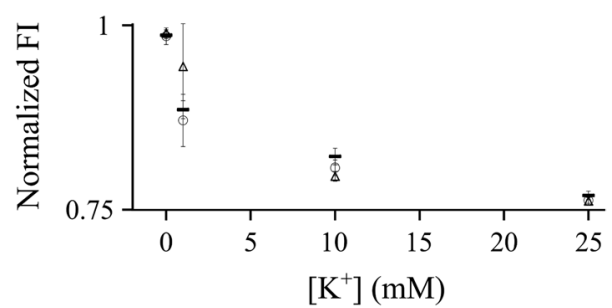

Fig. 1 Steady-state fluorescence intensity (FI) response to $\mathrm{K}^{+}$was measured as a function of the magnesium concentration in the buffer used to hybridize DNA nanosensors. Fluorescence intensity was normalized with respect to the DNA nanosensor fluorescence signal in the presence of the control buffer $\left(\mathrm{PB}+\mathrm{MgCl}_{2}\right)$, without $\mathrm{K}^{+}$. To optimize the concentration of magnesium in buffer, $\mathrm{K}^{+}$was added at concentrations of 0 , 1,10 , and $25 \mathrm{mM}$ to $1 \mu \mathrm{M}$ DNA nanosensor samples, each prepared with a buffer containing a different magnesium concentration: $0.85 \mathrm{mM}$ (large circle), $1.05 \mathrm{mM}$ (white up-pointing triangle), and $5 \mathrm{mM}$ (figure dash) 
temperature. The DNA nanosensor concentrations of $0,1,5,10,16.6$ and $33.3 \mu \mathrm{M}$ were used as $\mathrm{K}^{+}$was added sequentially. $\mathrm{K}^{+}$concentrations investigated were $0,1,5$, and $25 \mathrm{mM}$.

\section{DNA nanosensor ion selectivity measurement}

To enhance the selectivity of the nanosensor, EGTA (ethylene glycol-bis( $\beta$-aminoethyl ether)- $N, N, N^{\prime}, N^{\prime}$-tetraacetic acid) at a concentration of $3 \mathrm{mM}$ was added to samples containing $\mathrm{K}^{+}, \mathrm{Na}^{+}$, and $\mathrm{Ca}^{2+}$ and incubated at room temperature for 15 min to abrogate the interference of calcium ions [26]. The $0.5 \mu \mathrm{M}$ DNA nanosensor solution was then added and incubated for $2 \mathrm{~h}$ at room temperature, followed by fluorescent measurements. A fluorescence spectrometer was used to measure the fluorescence intensity of samples with and without EGTA. Samples were diluted by a factor of 10 and 100 times from physiological concentrations.

\section{Surface treatment of glass slides}

Standard 75-mm $\times 38$-mm glass slides (Thermo Fisher Scientific) were immersed in ethanol for $15 \mathrm{~min}$ for cleaning and dried with filtered nitrogen gas. The slides were exposed to oxygen plasma (Harrick Plasma, Plasmaflo) for $1 \mathrm{~min}$ to create $\mathrm{OH}^{-}$groups on the glass surface. The modified slides were immediately immersed in a $1 \% \mathrm{v} / \mathrm{v}$ (3-glycidyloxypropyl)trimethoxysilane solution for $20 \mathrm{~min}$ to allow the epoxy-silane to bond to the $\mathrm{OH}^{-}$groups on the slides. The treated glass slides were washed using deionized water, and dried quickly using filtered nitrogen gas.

\section{DNA nanosensor concentration sensitivity on glass slide}

DNA nanosensors were coated at different concentrations of $0,0.1,1,5,10,15,20$, and $25 \mu \mathrm{M}$ on treated glass slides. The DNA nanosensor fluorescence signal was measured at $37^{\circ} \mathrm{C}$ using epifluorescence microscopy. Images were acquired immediately after coating and the fluorescence intensity for each concentration was determined using ImageJ software (NIH, Bethesda, MD).

\section{Fabrication of DNA-based nanosensor microfluidic device}

The microfluidic device was fabricated using standard photolithography and soft lithography protocols. A master mold with a design of five parallel microfluidic channels was created using a silicon wafer. Polydimethylsiloxane (PDMS), mixed with a base/agent ratio of 10:1, was poured to completely cover the device mold. The PDMS was cured for $24 \mathrm{~h}$ at room temperature followed by $24 \mathrm{~h}$ at $65^{\circ} \mathrm{C}$ to minimize the effects of PDMS shrinking. The PDMS device was cut from the mold using a razor blade. The PDMS device was then bonded to the silane-treated glass slides by exposing the PDMS device and treated glass slide to oxygen plasma for $1 \mathrm{~min}$ in a plasma cleaner (Harrick Plasma, Plasmaflo), pressing the PDMS device onto the treated glass slides with even pressure, and heating the assembled device at $65^{\circ} \mathrm{C}$ for $30 \mathrm{~min}$.

The device channels were filled with a $25 \mu \mathrm{M}$ amino-modified DNA nanosensor solution using a syringe and incubated overnight at room temperature to allow the DNA nanosensors to immobilize through amine-epoxy binding [27]. Afterwards, the channels were washed ten times with buffer solution $\left(\mathrm{PB}+\mathrm{MgCl}_{2}\right)$ to remove excess 
unbonded oligonucleotides. The completed microfluidic device, functionalized with the DNA nanosensors, was analyzed at room temperature and stored at $4{ }^{\circ} \mathrm{C}$ until used. A syringe pump (PHD Ultra, Harvard Apparatus) was connected to the device inlet and infused at a rate of $0.02 \mathrm{~mL} / \mathrm{h}$ and yielded a shear rate of $91 \mathrm{~s}^{-1}$. These experiments were conducted at $37{ }^{\circ} \mathrm{C}$ and a minimum of three samples were analyzed for statistical significance.

\section{Results}

\section{DNA nanosensor formation}

In these experiments, fluorescence and quenching dyes FAM and DABCYL, respectively, are hybridized with scaffold oligonucleotides that provide a structure for the DNA nanosensor. In the absence of potassium, the fluorescence dye structure emits light, while it is quenched in the presence of potassium (Fig. 2). In our system, sensing the presence of $\mathrm{K}^{+}$depends on proper hybridization of the three oligonucleotides. We used PAGE gels to confirm stable hybridization of the fluorescence-emitting oligonucleotide (FAM), fluorescence-quenching oligonucleotide (DABCYL), and oligonucleotide scaffold molecule. To do this, we assessed the size of the structures of nine oligonucleotide samples, each containing one, two, or all three of the oligonucleotides (FAM, DABCYL, scaffold) used to form the $\mathrm{K}^{+}$DNA nanosensors. Different molar ratios of the three oligonucleotides were tested. The samples were hybridized at a temperature of $95^{\circ} \mathrm{C}$ for $5 \mathrm{~min}$ and incubated at room temperature for $15 \mathrm{~min}$ before they were run through the PAGE gel for $30 \mathrm{~min}$. After being run through the gel, the hybridized structure, composed of all three oligonucleotides, moved the least through the PAGE gel relative to individual oligonucleotides and incomplete structures, indicating that the three oligonucleotide molecules hybridized successfully to form the complete $\mathrm{K}^{+}$DNA nanosensor, creating a larger overall structure (Fig. 3). There are multiple faint bands in the columns that contain hybridized structures, indicating that the three oligonucleotides did not hybridize with $100 \%$ efficiency (Fig. 3). However, the locations of the bright bands indicate that the majority of oligonucleotides formed a larger structure that affected its movement down the column, confirming the successful formation of the DNA nanosensor complex.

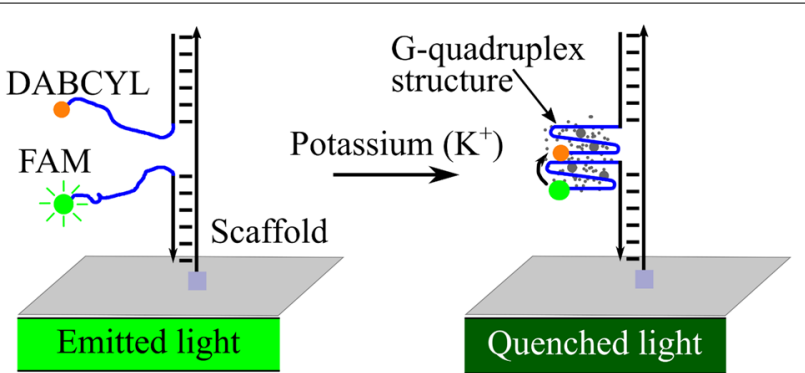

Fig. 2 The DNA nanosensors are composed of three hybridized oligonucleotides: a fluorophore (FAM), a quencher (DABCYL), and a scaffold oligonucleotide. In the presence of buffer, the DNA nanosensor complex fluoresces. When potassium is present, the DNA nanosensor complex forms a more compact G-quadruplex structure and brings the fluorophore and quencher closer together, causing the fluorescence signal to decrease 


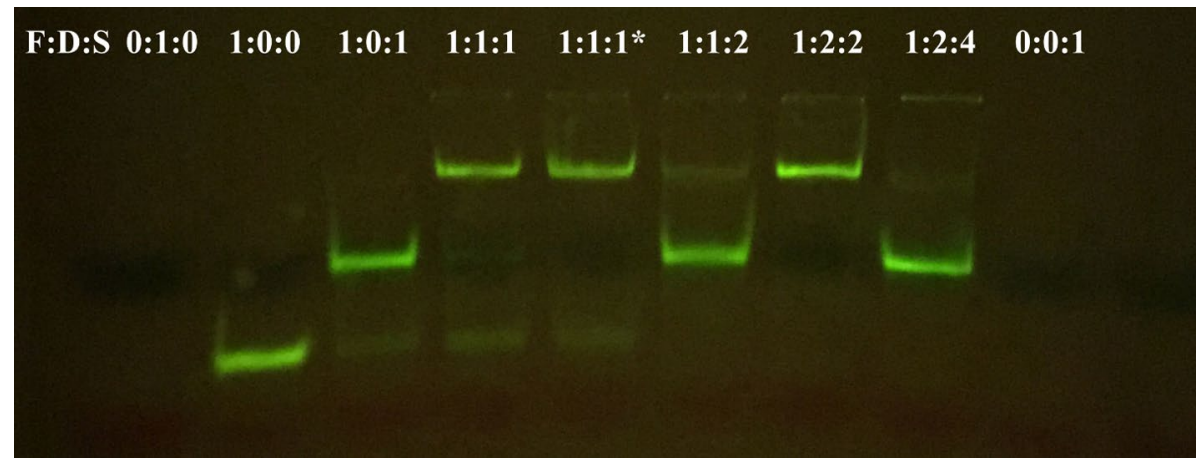

Fig. 3 PAGE gel results for different combinations and different molar ratios of the three oligonucleotides that make up the DNA nanosensor complex. Each well differs by the molar ratio of FAM:DABCYL:Scaffold
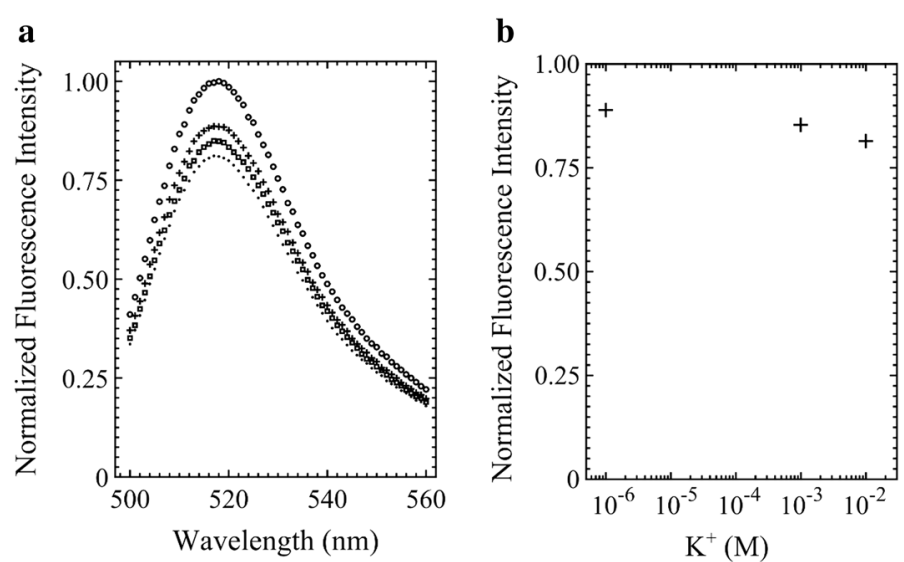

Fig. 4 Normalized fluorescence intensity as a function of potassium concentration. a The fluorescence intensity of the nanosensor with a concentration of $1 \mu \mathrm{M}$ was measured after adding $0 \mathrm{M}$ (control), white circle, $1 \mu \mathrm{M}$, plus sign, $1 \mathrm{mM}$, square, and $10 \mathrm{mM}$, black circle, $\mathrm{K}^{+}$. b The peak normalized fluorescence intensity decreases with increased $\mathrm{K}^{+}$. $\mathrm{PB}+\mathrm{MgCl}_{2}$ served as a control buffer

\section{Fluorescence spectrum measurement}

Once the formation of the DNA nanosensors was confirmed using the PAGE gel, the function of the nanosensors was tested using fluorescence spectrum assays with a fluorescence spectrometer. During these experiments, the fluorescence intensity was measured as a function of potassium concentration (Fig. 4a). To define a control fluorescence intensity level, fluorescence was measured in the presence of a control buffer $\left(\mathrm{PB}+\mathrm{MgCl}_{2}\right)$, without $\mathrm{K}^{+}$. Following the baseline measurement of the control buffer, $\mathrm{K}^{+}$was added with concentrations of $1 \mu \mathrm{M}, 1 \mathrm{mM}$, and $10 \mathrm{mM}$ in different wells, each containing $1 \mu \mathrm{M}$ DNA nanosensor solution. At the peak emission wavelength $(518 \mathrm{~nm})$, the normalized fluorescence intensity decreased by $11.1 \%, 14.7 \%$, and $18.6 \%$, respectively, for each concentration of $\mathrm{K}^{+}$when compared to the baseline measurement without $\mathrm{K}^{+}$. While higher concentrations of potassium caused a greater decrease in fluorescence intensity (Fig. 4a), the decrease in the fluorescence signal is not proportional to the concentration of potassium added (Fig. 4b). The lack 
of proportionality in the fluorescence signal decrease upon addition of potassium demonstrates an intrinsic non-linearity in the system.

\section{DNA nanosensor concentration sensitivity}

The function of the $\mathrm{K}^{+}$DNA nanosensor was further tested using a fluorescence spectrometer in real time (Fig. 5). Various concentrations of the DNA nanosensor were tested to optimize the sensor response upon adding $\mathrm{K}^{+}$. To define a control fluorescence intensity level, fluorescence was measured in the presence of the control buffer $\left(\mathrm{PB}+\mathrm{MgCl}_{2}\right)$ without $\mathrm{K}^{+}$. No obvious changes in fluorescence were observed. Following the baseline control measurements, $\mathrm{K}^{+}$was added serially to each sample to final concentrations of 1,10 , and $25 \mathrm{mM}$. Following the addition of $\mathrm{K}^{+}$, the fluorescence intensity signal was recorded after reaching steady state. The fluorescence signal for each DNA nanosensor concentration was normalized with respect to the fluorescence intensity of the corresponding nanosensor concentration in the control buffer $\left(\mathrm{PB}+\mathrm{MgCl}_{2}\right)$ without $\mathrm{K}^{+}$. A decrease in fluorescence was expected upon each individual addition of potassium since potassium binds to the DNA nanosensor leading to a conformational change that quenches the fluorescence signal. Once again, we observed a lack of proportionality in the change of the fluorescence level to the concentration of potassium added (Fig. 5), further demonstrating the non-linearity in the system. Increasing the DNA nanosensor concentration resulted in a larger relative signal decrease when $\mathrm{K}^{+}$was added, suggesting that larger concentrations of the DNA nanosensor have a more sensitive response to $\mathrm{K}^{+}$(Fig. 5).

\section{Immobilized DNA nanosensor concentration sensitivity}

All measurements shown up to here demonstrated that DNA nanosensors in solution are sensitive to $\mathrm{K}^{+}$. Next, we wanted to determine if the sensitivity of the DNA

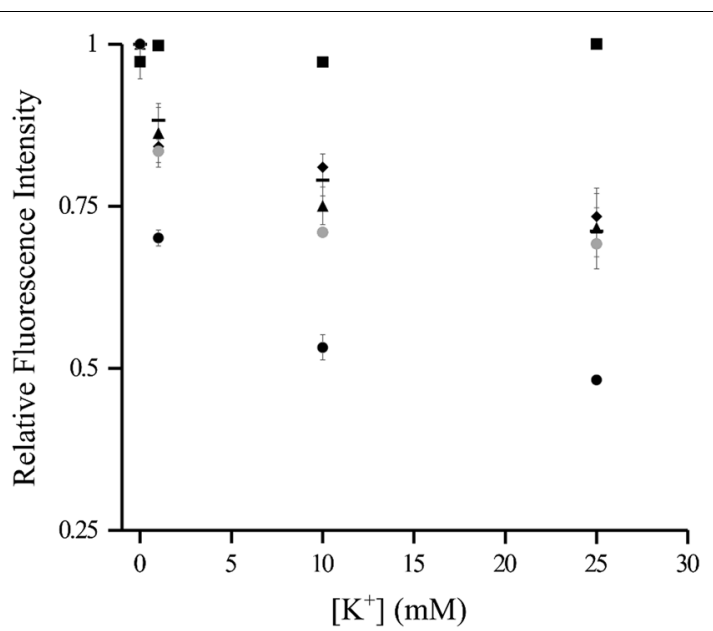

Fig. 5 Relative fluorescence intensity response was measured as a function of potassium concentration. The relative fluorescence intensity was independently normalized with respect to the fluorescence signal of the corresponding DNA nanosensor concentration in the presence of the control buffer $\left(\mathrm{PB}+\mathrm{MgCl}_{2}\right)$, without $\mathrm{K}^{+}$. To optimize the concentration of DNA sensors, $\mathrm{K}^{+}$was added at concentrations of $0,1,10$, and $25 \mathrm{mM}$ to DNA nanosensor samples of various concentrations: $0 \mu \mathrm{M}$ (black square), $1 \mu \mathrm{M}$ (figure dash), $5 \mu \mathrm{M}$ (black diamond), $10 \mu \mathrm{M}$ (black up-pointing triangle), $16.6 \mu \mathrm{M}$ (gray circle), and $33.3 \mu \mathrm{M}$ (black circle) 
nanosensor varied similarly when immobilized on a surface. DNA nanosensors were coated on a glass slide at varying concentrations that were relevant to the microfluidic device experiments. Figure 6 shows that at the 0 and $0.1 \mu \mathrm{M}$ DNA nanosensor concentration, the fluorescence signal measured by the camera is due to background noise. However, as the concentration increased from 1 to $25 \mu \mathrm{M}$, the normalized fluorescence intensity increased nonlinearly with the largest increase of $24 \%$ occurring from 20 to $25 \mu \mathrm{M}$ of DNA nanosensor.

\section{Microfluidic device experiment}

To further demonstrate the possibility of these $\mathrm{K}^{+}$DNA nanosensors being incorporated into a point-of-care device, multiple channels in a microfluidic device were coated with the potassium DNA nanosensors (Fig. 7a). For a greater signal-to-noise ratio, the highest concentration solution of $25 \mu \mathrm{M}$ was used for the coating of DNA nanosensors on the surface of the microfluidic channels. Channels were infused with either a control buffer solution $\left(\mathrm{PB}+\mathrm{MgCl}_{2}\right)$ or a potassium chloride $(\mathrm{KCl})$ solution for at least $14 \mathrm{~min}$. The fluorescence signal was monitored via periodic image acquisition using epifluorescence microscopy. After 14 min of infusion with the control buffer, no significant fluorescence signal change was observed (Fig. 7b). However, a significant decrease in fluorescence signal was observed when the $\mathrm{K}^{+}$DNA nanosensors were exposed to 5 and $7 \mathrm{mM} \mathrm{KCl}$ in solution, which is within the physiological range of serum potassium (Fig. 7b). When the flow of $5 \mathrm{mM} \mathrm{KCl}$ contacted the $\mathrm{K}^{+}$DNA nanosensors at the 1-min mark, the fluorescence signal decreased initially by $2.2 \%$. Each minute following, the fluorescence signal decreased gradually, by percent decreases of 3.1, 4.5, and 4.7, respectively, before reaching a near-constant fluorescence intensity value after $4 \mathrm{~min}$ of infusion. In contrast, when the flow of $7 \mathrm{mM} \mathrm{KCl}$ contacted the $\mathrm{K}^{+}$DNA nanosensors at the 1-min mark, the fluorescence signal decreased substantially by $20.8 \%$. The fluorescence signal then decreased gradually, by percent decreases of $21.9,22.2$, and 22.5 , respectively, before reaching a near-constant fluorescence intensity value. Although no major changes in fluorescence signal were observed after $4 \mathrm{~min}$, the system was allowed to run for an additional $10 \mathrm{~min}$ to ensure attainment of a steady-state signal. These data demonstrate that bound DNA nanosensors can provide a spatial temporal signal of the presence of

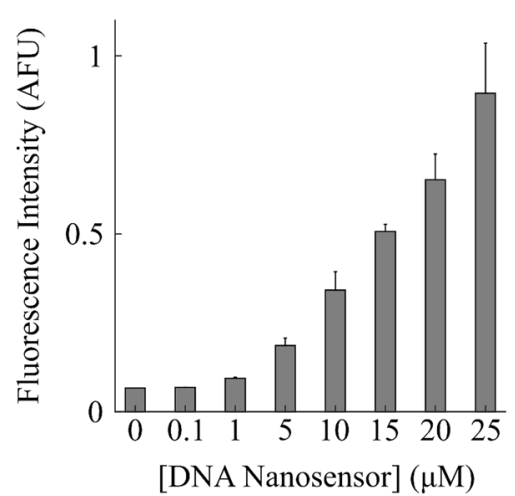

Fig. 6 Fluorescence intensity measurements from DNA nanosensors coated on a glass slide at different concentrations of $0,0.1,1,5,10,15,20$, and $25 \mu \mathrm{M}$ 


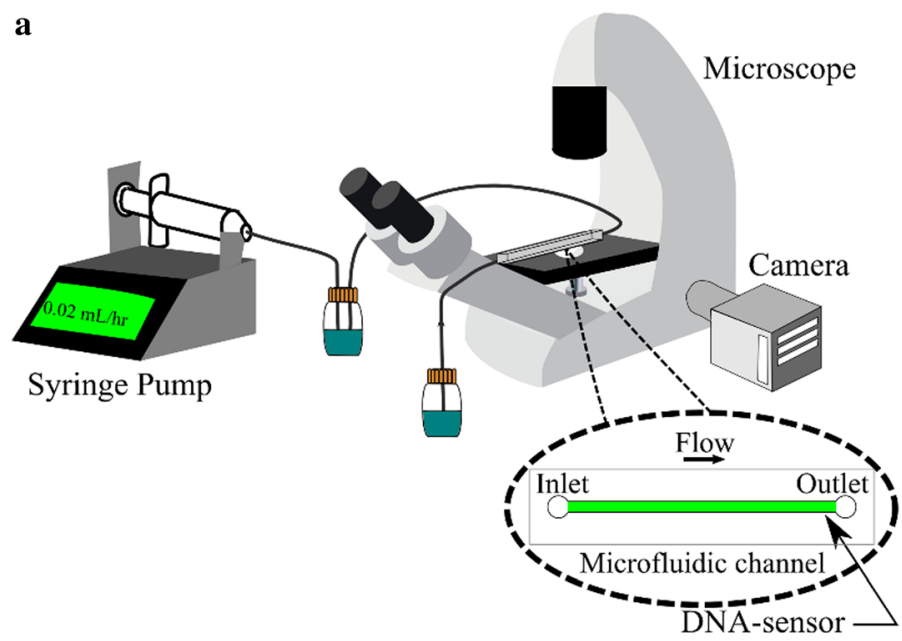

b

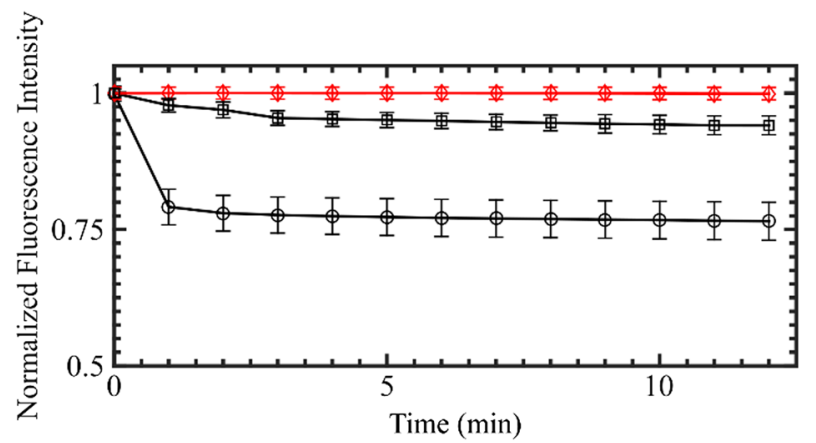

Fig. 7 a DNA nanosensors with a concentration of $25 \mu \mathrm{M}$ were immobilized on the bottom surface of a microfluidic device channel. The microfluidic device was infused with a syringe pump and imaged with microscope. $\mathbf{b} \mathrm{A} \mathrm{PB}+\mathrm{MgCl}_{2}$ buffer (control) or $\mathrm{KCl}$ solution was run through the channel at $0.02 \mathrm{~mL} / \mathrm{h}$ for $14 \mathrm{~min}$. The normalized integrated fluorescence signal remained constant for the $\mathrm{PB}+\mathrm{MgCl}_{2}$ buffer solution, lozenge, while the channels infused with $5 \mathrm{mM} \mathrm{KCl}$, square, or $7 \mathrm{mM} \mathrm{KCl}$, circle, decreased temporally

potassium in a solution at physiological concentrations. $\mathrm{K}^{+}$was able to quench the fluorescence signal emitted by the DNA-based nanosensor over time in the device while the control buffer did not.

\section{DNA nanosensor ion selectivity measurement}

DNA-based oligonucleotide nanosensors that can measure $\mathrm{K}^{+}$using G-quadruplex can only serve as a viable alternative technology if sufficiently selective. The selectivity of the DNA nanosensor was tested in the presence and absence of $\mathrm{Na}^{+}, \mathrm{Ca}^{2+}$ or $\mathrm{K}^{+}$for varying concentrations. First, the fluorescence intensity of the DNA nanosensors was measured in the absence of $\mathrm{Na}^{+}, \mathrm{Ca}^{2+}$ and $\mathrm{K}^{+}$to establish a baseline (Fig. 8a). The normal concentration of $\mathrm{Na}^{+}$in human blood is about $140 \mathrm{mM}$. This concentration of sodium decreased fluorescence intensity by about $4.8 \%$, which was very similar to the $6.2 \%$ and

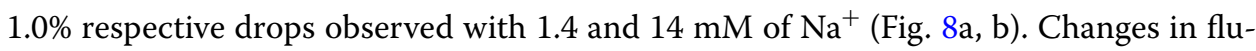
orescence intensity were quantified only at the peak intensity point, which coincided with the $518 \mathrm{~nm}$ wavelength. Similarly, $\mathrm{Ca}^{2+}$ ions at the physiological concentration of $2.4 \mathrm{mM}, 0.24 \mathrm{mM}$ and $0.024 \mathrm{mM}$ decreased the fluorescence intensity by $20 \%, 5.9 \%$, and 

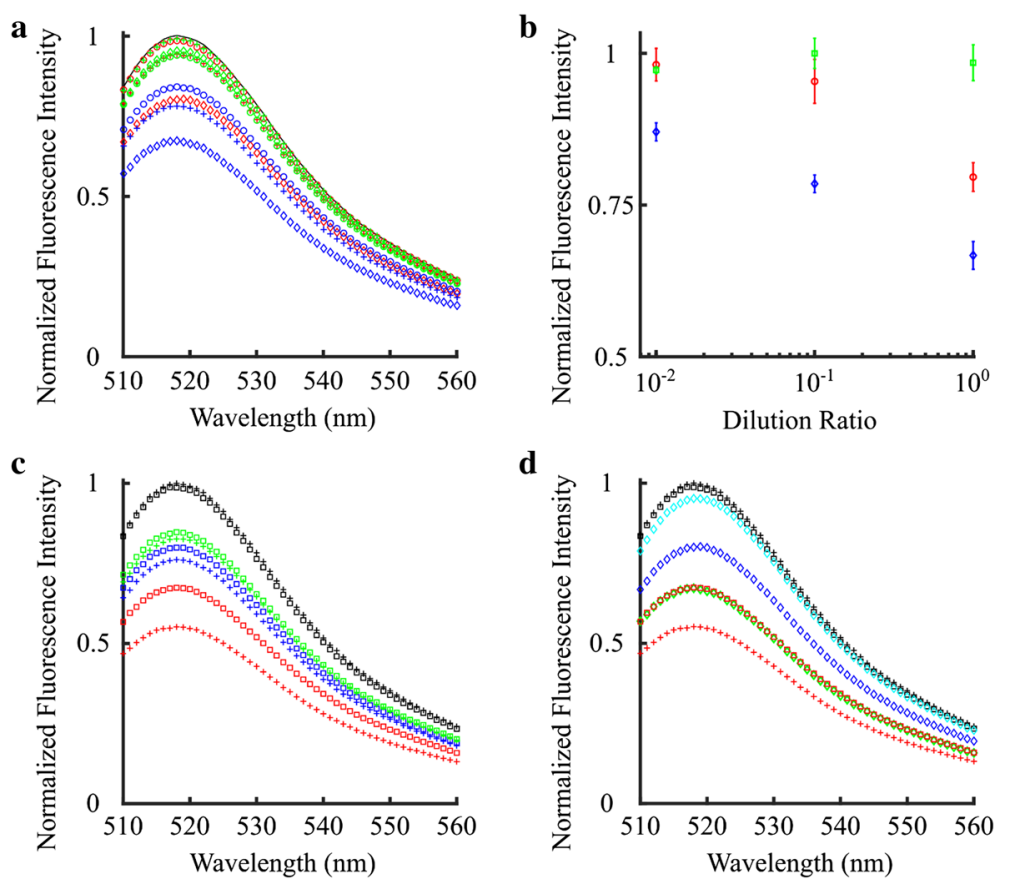

Fig. 8 a DNA nanosensor selectivity for buffer solutions with no additional ions (black), figure dash $0 \mathrm{mM}$, $\mathrm{Na}^{+}$(green), circle $1.4 \mathrm{mM},+14 \mathrm{mM}$, lozenge $140 \mathrm{mM}, \mathrm{Ca}^{2+}$ (red), circle $0.024 \mathrm{mM},+0.24 \mathrm{mM}$, lozenge $2.4 \mathrm{mM}$, and $\mathrm{K}^{+}$(blue), circle $0.1 \mathrm{mM},+1 \mathrm{mM}$, lozenge $10 \mathrm{mM}$. b DNA nanosensor selectivity at optimal wavelength $(518 \mathrm{~nm})$ for $\mathrm{Na}^{+}$(green), square, $\mathrm{Ca}^{2+}$ (red), circle, and $\mathrm{K}^{+}$(blue), lozenge, for three different dilutions $1 \times, 0.1 \times$, and $0.01 \times$. c DNA nanosensor selectivity for buffer solutions with no additional ions (black), and three different dilutions $0.01 \times\left(\mathrm{Na}^{+} 1.4 \mathrm{mM}, \mathrm{Ca}^{2+} 0.024 \mathrm{mM}, \mathrm{K}^{+} 0.1 \mathrm{mM}\right.$, green), $0.1 \times\left(\mathrm{Na}^{+}\right.$ $14 \mathrm{mM}, \mathrm{Ca}^{2+} 0.24 \mathrm{mM}, \mathrm{K}^{+} 1 \mathrm{mM}$, blue), and $1 \times\left(\mathrm{Na}^{+} 140 \mathrm{mM}, \mathrm{Ca}^{2+} 2.4 \mathrm{mM}, \mathrm{K}^{+} 10 \mathrm{mM}\right.$, red), with, square, or without, plus sign, EGTA. $\mathbf{d}$ DNA nanosensor selectivity for buffer solutions with no additional ions (black) plus sign $0 \mathrm{mM}, \mathrm{Na}^{+}$(cyan) lozenge $140 \mathrm{mM}, \mathrm{Ca}^{2+}$ (blue) lozenge $2.4 \mathrm{mM}, \mathrm{K}^{+}$(green) lozenge $10 \mathrm{mM}$, and all three ions $\left(\mathrm{Na}^{+} 140 \mathrm{mM}, \mathrm{Ca}^{2+} 2.4 \mathrm{mM}, \mathrm{K}^{+} 10 \mathrm{mM}\right.$, red) plus sign without EGTA. EGTA is added to the buffer solutions with no additional ions (black) square $0 \mathrm{mM}$ and all three ions $\left(\mathrm{Na}^{+} 140 \mathrm{mM}, \mathrm{Ca}^{2+} 2.4 \mathrm{mM}, \mathrm{K}^{+}\right.$ $10 \mathrm{mM}$, red) square

$1.6 \%$, respectively. The largest changes were observed when $\mathrm{K}^{+}$was added. The addition of $\mathrm{K}^{+}$at 10, 1.0 and $0.1 \mathrm{mM}$ caused the fluorescence intensity to decrease by $32.8 \%$, $22.1 \%$ and $16 \%$, respectively. These results demonstrated that the DNA nanosensor was more selective for $\mathrm{K}^{+}$than $\mathrm{Na}^{+}$, but still sufficiently selective for $\mathrm{Ca}^{2+}$ to affect the measurements.

To address the moderate selectivity of $\mathrm{Ca}^{2+}$ by the DNA nanosensors, the experiments from Fig. 8a were repeated by including or excluding EGTA, a calcium chelator. As a control, the DNA nanosensor fluorescence intensity was measured in the absence of $\mathrm{Na}^{+}, \mathrm{Ca}^{2+}$, and $\mathrm{K}^{+}$ions, and the intensity did not change with the addition of EGTA (Fig. 8c). Diluting the physiologically relevant $\mathrm{Na}^{+}, \mathrm{Ca}^{2+}$, and $\mathrm{K}^{+}$cation concentration by 100 times decreased fluorescence intensity by $17.4 \%$, while adding EGTA to this cation concentration decreased the fluorescence signal by $15.2 \%$. Although similar in trend, a slightly larger effect due to EGTA was observed when the cation concentration was diluted by ten times yielding a $23.8 \%$ and $20 \%$ decrease in fluorescence intensity without and with EGTA, respectively. However, the greatest effect due to EGTA was observed at physiologically relevant cation concentrations. Adding $140 \mathrm{mM} \mathrm{Na}^{+}, 2.4 \mathrm{mM} \mathrm{Ca}^{2+}$, and 
$10 \mathrm{mM} \mathrm{K}^{+}$decreased the fluorescence intensity by $44.8 \%$, while the addition of EGTA yielded a smaller decrease of $32.6 \%$.

Importantly, when adding $\mathrm{Na}^{+}, \mathrm{Ca}^{2+}$, or $\mathrm{K}^{+}$independently at the corresponding physiological concentrations, the DNA nanosensor clearly shows greater selectivity for $\mathrm{K}^{+}$ (Fig. 8d). The presence of $10 \mathrm{mM} \mathrm{K}^{+}$alone decreased the fluorescence intensity by $32.8 \%$, while adding all three cations simultaneously, decreased the signal by $44.8 \%$. However, addition of EGTA to the solution with all three cations at approximately physiological concentrations decreased the fluorescence signal only by $32.6 \%$, completely abrogating the effects of $\mathrm{Ca}^{2+}$ as shown at the peak wavelength of $518 \mathrm{~nm}$. The value of $32.6 \%$ with all three cations and EGTA is comparable to the $32.8 \%$ percent intensity decrease with $\mathrm{K}^{+}$alone, demonstrating that the DNA nanosensor can be used for selective $\mathrm{K}^{+}$detection in the presence of EGTA.

\section{Discussion}

To the best of our knowledge, these are the first sets of experiments to demonstrate a simple proof-of-concept microfluidic device to measure potassium in a flowing solution using DNA-based G-quadruplex nanosensors. Low flow rate laminar flows were used to infuse the channels [28]. However, higher flow rates (data not shown) can be employed, yielding much faster fluorescence-quenching rates. In these experiments, a homogeneous solution was used. In a heterogeneous solution like blood, pulsatile flow with a retrograde component can be employed to promote mixing, ensuring that a uniform concentration of electrolytes interacts with the $\mathrm{K}^{+}$DNA nanosensors.

These experiments were designed to demonstrate the validity of point-of-care potassium-measuring devices for potential future use at the point of care for hemodialysis patients. The concentrations of $5 \mathrm{mM}$ and $7 \mathrm{mM} \mathrm{KCl}$ tested in the buffer solution match physiological potassium blood concentration levels, and are relevant to hemodialysis patients $[13,29,30]$. Future studies can be conducted to optimize the G-quadruplex potassium nanosensors to reduce the influence from serum molecules that may alter the signal and more accurately measure physiological potassium concentrations in whole blood. It has been previously demonstrated that an optimized G-quadruplex sequence can measure potassium selectively in blood, without interference from competitive ions at physiological concentrations [22]. To demonstrate selectivity, our study used EGTA to abrogate the influence of calcium, which is completely feasible for clinical practice since calcium chelators are routinely used to inhibit coagulation during blood draws [31].

The novelty in this research arises from being able to use a lab-on-a-chip device that, if mass produced, can potentially cost less than current techniques and can measure molecules in blood quickly with high accuracy and with less blood volume required [32]. In contrast, the current procedure is to draw blood from a patient once a month on average, send it to a laboratory and wait at least $24 \mathrm{~h}$ for the blood test results [33]. Although this novel technology has the potential of being less expensive, the most important benefit is that the hemodialysis session can be modified instantaneously for each patient, transforming traditional hemodialysis to personalized medical therapy, where the bloodfiltering needs of each patient are fine-tuned similar to the physiological kidney function. If key electrolytes like potassium could be monitored more efficiently to provide an 
individual profile for each patient, treatments could be more personalized and complications such as sudden cardiac death may be decreased.

\section{Conclusions}

We present proof-of-concept results for a microfluidic lab-on-a-chip device with external dimensions less than $2 \mathrm{~cm}$ that can quickly and accurately measure potassium using a minute amount of fluid. Our device utilizes novel DNA-based fluorescence oligonucleotide nanosensors to detect the presence of potassium flowing through a microfluidic channel, as an initial proof-of-concept for a lab-on-a-chip point-of-care device. After exposing the lab-on-a-chip nanosensor to potassium for approximately $4 \mathrm{~min}$, a decrease in fluorescence signal was observed compared to control cases with buffer. Other commercially available devices require larger samples of blood and $24 \mathrm{~h}$ of turnaround time to receive results, a burden that can be avoided using a microfluidic device. This device would need further optimization to enhance uniform binding to a surface and improve sensitivity and selectivity before being considered in the clinics. Eventually, this device can be integrated with routine hemodialysis sessions to measure blood contents multiple times throughout a hemodialysis session, enabling protocol adjustment similar to a healthy kidney, which is presently unavailable. Sampling multiple drops of blood per session can reduce costs by limiting medical complications, avoid unnecessary venipuncture, and provide a real-time assessment of the patient's health. This labon-a-chip device may allow hemodialysis centers to provide personalized medicine to patients, potentially reducing mortality rates and increasing quality of life.

Acknowledgements

We thank Dr. Melissa D. Sánchez for constructive criticism.

\section{Authors' contributions}

AFS, BZ, MY, and JMJ conceived and designed the experiments; AFS, BZ, and JMJ performed the experiments; AFS, BZ, and JMJ analyzed the data; MY and JMJ contributed reagents/materials/analysis tools; AFS and JMJ wrote the paper. All authors read and approved the final manuscript.

Funding

This work was supported in part by the NIH National Heart, Lung, and Blood Institute (NHLBI) Grant K25 HL107617 (to J. M. Jiménez).

Availability of data and materials

Data related to the current study are available from the corresponding author on reasonable request.

\section{Consent for publication}

All the authors of the paper approved the publication of the article.

Competing interests

The authors declare that they have no competing interests.

\section{Author details}

${ }^{1}$ Department of Mechanical \& Industrial Engineering, University of Massachusetts Amherst, Amherst, MA 01003, USA.

2 Department of Chemistry, University of Massachusetts Amherst, Amherst, MA 01003, USA.

Received: 31 December 2018 Accepted: 29 May 2019

Published online: 11 June 2019

\section{References}

1. Saran R, et al. US renal data system 2018 annual data report: epidemiology of kidney disease in the United States. Am J Kidney Dis. 2019. https://doi.org/10.1053/j.ajkd.2019.01.001.

2. De Paula FM, et al. Clinical consequences of an individualized dialysate sodium prescription in hemodialysis patients. Kidney Int. 2004;66:1232-8.

3. Beto JA, Bansal VK, Kahn S. The effect of blood draw methodology on selected nutritional parameters in chronic renal failure. Adv Ren Replace Ther. 1999;6:85-92. 
4. Moore LW, Acchiardo S, Sargent JA, Burk L. Incidence, causes, and treatment of iron deficiency anemia in hemodialysis patients. J Ren Nutr. 1992;2:105-12.

5. Wizemann V, Buddensiek P, de Boor J, Grebe S, Schütterle G. Gastrointestinal blood loss in patients undergoing maintenance dialysis. Kidney Int Suppl. 1983;16:S218-20.

6. Conrad ME. Iron deficiency anemia. New York: Films Media Group; 2013

7. Choi HY, Ha SK. Potassium balances in maintenance hemodialysis. Electrolytes Blood Press. 2013;11:9.

8. Lee $\mathrm{S}$, et al. Lower serum potassium associated with increased mortality in dialysis patients: a nationwide prospective observational cohort study in Korea. PLoS ONE. 2017;12:e0171842.

9. Al-Saffar A-MH. Pre and post haemodialysis: the effect of electrolyte imbalance on ECGs of patients with end stage renal disease. Med J Babylon. 2011;8:221-9.

10. Herzog CA. Cardiac arrest in dialysis patients: approaches to alter an abysmal outcome. Kidney Int. 2003;63:S197-200.

11. Saravanan P, Davidson NC. Risk assessment for sudden cardiac death in dialysis patients. Circ Arrhythmia Electrophysiol. 2010;3:553-9.

12. Karaboyas A, et al. Dialysate potassium, serum potassium, mortality, and arrhythmia events in hemodialysis: results from the dialysis outcomes and practice patterns study (DOPPS). Am J Kidney Dis. 2017. https://doi.org/10.1053/j. ajkd.2016.09.015.

13. Kovesdy CP, et al. Serum and dialysate potassium concentrations and survival in hemodialysis patients. Clin J Am Soc Nephrol. 2007;2:999-1007.

14. Makar MS, Pun PH. Sudden cardiac death among hemodialysis patients. Am J Kidney Dis. 2017:69:684-95.

15. Uhlin F, Fridolin I, Lindberg L-GR, Magnusson M. Estimation of delivered dialysis dose by on-line monitoring of the ultraviolet absorbance in the spent dialysate. Am J Kidney Dis. 2003:41:1026-36.

16. Tusa JK, He H. Critical care analyzer with fluorescent optical chemosensors for blood analytes. J Mater Chem. 2005:15:2640

17. Englich FV, et al. Photoinduced electron transfer based ion sensing within an optical fiber. Sensors (Basel). 2011;11:9560-72.

18. Gotch F, Evans M, Metzner K, Westphal D, Polaschegg H. An on-line monitor of dialyzer Na and K flux in hemodialysis. ASAIO Trans. 1990;36:M359-61.

19. Burnett RW, et al. Recommendations for measurement of and conventions for reporting sodium and potassium by ion-selective electrodes in undiluted serum, plasma or whole blood. Clin Chem Lab Med. 2000;38:1065-71.

20. Cowell DC, et al. Sodium and potassium ion selective electrodes: a review of theory and calibration. Med Lab Sci. 1985:42:252-61.

21. Takenaka S, Juskowiak B. Fluorescence detection of potassium ion using the G-quadruplex structure. Anal Sci. 2011;27:1167-72.

22. Yang L, et al. Direct fluorescent detection of blood potassium by ion-selective formation of intermolecular G-quadruplex and ligand binding. Anal Chem. 2016;88:9285-92.

23. Sharma MK, Wieringa FP, Frijns AJH, Kooman JP. On-line monitoring of electrolytes in hemodialysis: on the road towards individualizing treatment. Expert Rev Med Devices. 2016;13:933-43.

24. Rhodes D, Lipps HJ. G-quadruplexes and their regulatory roles in biology. Nucleic Acids Res. 2015;43:8627-37.

25. Asirvatham JR, Moses V, Bjornson L. Errors in potassium measurement: a laboratory perspective for the clinician. N Am J Med Sci. 2013;5:255-9.

26. Fisher AEO, Hague TA, Clarke CL, Naughton DP. Catalytic superoxide scavenging by metal complexes of the calcium chelator EGTA and contrast agent EHPG. Biochem Biophys Res Commun. 2004;323:163-7.

27. Chiu S-K, et al. Synergistic effects of epoxy- and amine-silanes on microarray DNA immobilization and hybridization. Biochem J. 2003;374:625-32.

28. Song H, Tice JD, Ismagilov RF. A microfluidic system for controlling reaction networks in time. Angew Chemie Int Ed. 2003:42:768-72

29. Bakris $\mathrm{GL}$, et al. Effect of patiromer on serum potassium level in patients with hyperkalemia and diabetic kidney disease. JAMA. 2015:314:151

30. Gifford JD, Rutsky EA, Kirk KA, McDaniel HG. Control of serum potassium during fasting in patients with end-stage renal disease. Kidney Int. 1989;35:90-4.

31. Banfi G, Salvagno GL, Lippi G. The role of ethylenediamine tetraacetic acid (EDTA) as in vitro anticoagulant for diagnostic purposes. Clin Chem Lab Med. 2007:45:565-76.

32. Whitesides GM. The origins and the future of microfluidics. Nature. 2006;442:368-73.

33. Day C. Haemodialysis blood results. Queen Elizabeth Hospital Birmingham, NHS Foundation Trust; 2017. https:// www.uhb.nhs.uk/Downloads/pdf/PiHaemodialysisBloodResults.pdf

\section{Publisher's Note}

Springer Nature remains neutral with regard to jurisdictional claims in published maps and institutional affiliations. 